\title{
Structural Distribution of Linear Low-Density Polyethylenes
}

\author{
Satoru HosodA \\ Chiba Research Laboratory, Sumitomo Chemical Co., Ltd., \\ Ichihara-shi, Chiba 299-01, Japan
}

(Received November 4, 1987)

\begin{abstract}
Molecular and crystalline structures of linear low-density polyethylenes (LLDPE) were investigated by a series of characterization techniques. Molecular structural characteristics were elucidated by temperature-rising elution fractionation (TREF) and solventgradient elution fractionation (SGEF). A bird's eye view and a contour map of LLDPE obtained by a combination of TREF and size exclusion chromatography exhibited a broad and multimodal chemical composition distribution (CCD), in contrast to a sharp and single CCD of conventional high-pressure low-density polyethylene (HP-LDPE). Short chain branching (SCB) was found to decrease with increase of molecular weight by SGEF technique. Thermal analysis of cross-fractions proved that a characteristic broad endothermic curve of LLDPE is attributable to its broad and multimodal CCD. Then, using DSC results, an indicative index (DI) which expresses the degree of the distribution of lamellar crystal thickness is proposed. DI was found to be sensitive both to CCD and to a kind of SCB. The crystallinity and melting temperature of cross-fractions having comparable molecular weights decrease with increasing comonomer content in the order of octene$1 \approx 4$-methyl-pentene- $1>$ hexene-1 $>$ butene- 1 . From a statistical approach to the relationship between crystallinity and degree of SCB, the probability of exclusion of a bulky branching such as isobutyl from a crystalline lattice is considered to be twice as large as than that of ethyl branching.

KEY WORDS Linear Low-Density Polyethylene (LLDPE) / High-Pressure

Low-Density Polyethylene (HP-LDPE) / Structural Distribution /

Fractionation / Chemical Composition Distribution / Short Chain Branching / Crystallinity / Melting Temperature /
\end{abstract}

In the last decade, interest has grown greatly in linear low-density polyethylene (LLDPE) manufacturing all over the world and LLDPE has gradually replaced conventional high pressure low-density polyethylene (HP-LDPE) through its superior mechanical and thermal properties. Needless to say, LLDPE has short chain branchings (SCB) derived from comonomer units which are $\alpha$-olefins, such as butene-1, hexene-1, octene-1, and 4-methylpentene-1. Thus, the molecular structure of LLDPE should be investigated from view points of average content of comonomer (degree of SCB), monomer sequence distribution along a polymer chain (intramolecular distribution of SCB), and distribution of comonomer among polymers (intermolecular dis- tribution of SCB) besides average molecular weight and molecular weight distribution. Recently, investigations for chemical composition distribution (CCD) of LLDPE which is considered to have an important role in final properties $^{1}$ are receiving increasing attention and its inhomogeneity has been elucidated by means of various methods. ${ }^{1-7}$ But relatively little has been reported on the details of CCD and the effects of CCD on super structure. The authors have already reported the superstructure of $L_{L D P E}{ }^{8-11}$ and found that LLDPE has wide distribution of the superstructure compared to HP-LDPE. In this paper, detail studies on CCD of LLDPE by fractionation techniques and its influence on lamellar crystal are considered. 


\section{EXPERIMENTAL}

\section{Materials}

The LLDPEs used are listed in Table I. Some of them are commercial products and the others are polymerized in our laboratory with the use of the catalyst system composed of $\mathrm{MgCl}_{2}$ supported $\mathrm{TiCl}_{4}$ and triethyl aluminum. ${ }^{12}$

\section{Fractionation of Polymers}

For fractionation by molecular weight, solvent-gradient elution fractionation (SGEF) was carried out at $120^{\circ} \mathrm{C}$ using both xylene (solvent) and ethyl cellosolve (nonsolvent). About $30 \mathrm{~g}$ of polymer were precipitated from xylene solution on sand by gradually lowering the temperature. This polymer coated sand was introduced into a column and the preheated solvent/nonsolvent mixture was continuously added into the column. The solvent/ nonsolvent volume ratio was varied from 0.7 to 2.2. To avoid oxidative degradation of polymer during the course of fractionation, $0.5 \%$ Sumilizer BHT (Sumitomo Chemical Co., Ltd.) was added to the extraction mixture and operations were carried out under nitrogen.

Fractionation based on crystallinity for the purpose of achieving compositional separation was carried out by means of the temperaturerising elution fractionation (TREF) $)^{13,14}$ using xylene as the extracting solvent. The extraction temperature was raised stepwise in small intervals over the range of $25-120^{\circ} \mathrm{C}$ and $17-$ 18 fractions were obtained. In both fractionations, the polymer eluted was withdrawn by reprecipitation from methyl alcohol. Recoveries were above $98 \%$ for all samples studied.

\section{Characterization of Polymers}

Molecular weight and molecular weight distribution (MWD) were measured using a TOYOSODA HLC 811 equipped with both a refractometer and a Chromatix low-angle
Table I. Samples of linear low-density polyethylene and high-pressure low-density polyethylene

\begin{tabular}{|c|c|c|c|c|}
\hline \multirow{2}{*}{ Sample } & $\mathrm{MFR}^{\mathrm{a}}$ & Density $^{b}$ & \multirow{2}{*}{ Comonomer } & \multirow{2}{*}{$\frac{\mathrm{SCB}^{\mathrm{c}}}{1 / 1000 \mathrm{C}}$} \\
\hline & $\mathrm{g} / 10 \mathrm{~min}$ & $\mathrm{~g} \mathrm{~cm}^{-3}$ & & \\
\hline A & 0.8 & 0.920 & Butene-1 & 20.1 \\
\hline B & 0.8 & 0.919 & Butene-1 & 17.4 \\
\hline $\mathrm{C}$ & 0.8 & 0.920 & Butene-1 & 17.5 \\
\hline $\mathrm{D}$ & 0.8 & 0.920 & Butene-1 & 14.3 \\
\hline $\mathrm{E}$ & 0.9 & 0.921 & Hexene-1 & 13.2 \\
\hline $\mathrm{F}$ & 2.1 & 0.919 & $\begin{array}{l}\text { 4-Methyl- } \\
\text { pentene-1 }\end{array}$ & 14.1 \\
\hline G & 1.0 & 0.921 & Octene-1 & 11.0 \\
\hline $\mathrm{H}$ & 2.0 & 0.921 & $(\text { HP-LDPE })^{d}$ & 22.0 \\
\hline
\end{tabular}

${ }^{a}$ Measured at $190^{\circ} \mathrm{C}$.

b Measured at $23^{\circ} \mathrm{C}$.

c Determined from infrared spectrum.

d High-pressure low-density polyethylene.

laser light scattering (LALLS) apparatus. Instrumental spreading for MWD of fraction by SGEF was corrected following Ishige et al. ${ }^{15}$ The inherent viscosity of the fraction by SGEF was measured in trichlorobenzene solvent at $135^{\circ} \mathrm{C}$ and molecular weight was calculated using the following Equation. ${ }^{16}$ $[\eta]=4.86 \times 10^{-4} \bar{M}_{w}^{0.705}$.

The degree of SCB was determined by infrared spectroscopy, using methyl symmetric deformation band at $1378 \mathrm{~cm}^{-1}$ (for normal alkyl branch) or at $1384 \mathrm{~cm}^{-1}$ (for isobutyl branch). Since the contribution to the 1378 $\mathrm{cm}^{-1}$ band from methyl group attached to the end of main chain is considerably large for a small molecule, correction was made by substituting one methyl group per polymer molecule assuming that one end group of LLDPE is vinyl or vinylidene occurred by $\beta$-elimination from growing species during polymerization.

The thickness of lamellar crystal $\left(L_{\mathrm{c}}\right)$ was calculated from the following relationship, considering a two-phase model for polyethylene solid state;

$$
L_{\mathrm{c}}=0.85 X_{\mathrm{c}} L /\left(1-0.15 X_{\mathrm{c}}\right)
$$

where $L$ is a long period determined by small 
angle X-ray scattering (SAXS), $X_{\mathrm{c}}$ the crystallinity in weight fraction, and the density of crystalline and amorphous phases of polyethylene were taken to be 1.00 and 0.85 , respectively. ${ }^{17} \mathrm{XRD}$ and SAXS were measured with a Rigaku RAD-RB X-ray diffractometer. Samples used here were molded into a sheet in a hot-press and quenched in a water-cooled press.

Exothermic and endothermic curves were measured using a Perkin Elmer DSC Model 2. In a general measurement, a DSC sample of about $5 \mathrm{mg}$ was held at $150^{\circ} \mathrm{C}$ for $5 \mathrm{~min}$, cooled and heated at the rate of $5^{\circ} \mathrm{C} \min ^{-1}$. Heat of fusion $(\Delta H)$ was calculated from the area of the endothermic curve using indium standard sample $\left(6.8 \mathrm{cal} \mathrm{g}^{-1}\right)$.

${ }^{13} \mathrm{C}$ NMR spectra were obtained on a Bruker AM400 spectrometer operating at $100.6 \mathrm{MHz}$ at $120^{\circ} \mathrm{C}$. Polymer solutions for NMR measurements were prepared in 1,2dichlorobenzene/deuterobenzene- $d_{6}$ with concentration maintained $7 \%$ by weight. Tetramethyl silane was used as a chemical shift reference. The conditions for measurement were as follows: pulse interval, $10 \mathrm{~s}$; acquisition time, $3 \mathrm{~s}$; pulse width, $8.5 \mu \mathrm{s}\left(90^{\circ}\right)$; spectral width, $8000 \mathrm{~Hz}$; number of data points per spectrum, $32 \mathrm{~K}$. Triad sequence distribution, average sequence length, and run number in ethylene/butene-1 copolymers were calculated from ${ }^{13} \mathrm{C}$ NMR spectra using the method proposed by Hsieh et al. ${ }^{18}$

\section{Representations for Structural Distribution}

The structural distribution for a whole polymer was expressed by two methods. One of them is a bird's eye view, obtained by montage drawings of MWD curves of TREF fractions. Each curve was drawn in proportion to the weight fraction in the whole polymer. The elution time is converted to molecular weight using the calibration curve made for standard polystyrenes and taking a conversion-factor $(Q)$ to be 17.7 for polyethylene. ${ }^{19}$ The final Bird's eye view was drawn filling the space at regular intervals for the degree of SCB using a micro-computer. The angles of the view-point were taken to be $170^{\circ}$ to the molecular weightheight plane and $40^{\circ}$ to the molecular weightSCB plane in this study.

The other method used is a contour map. First, the relative height at a certain molecular weight was accumulated for all the MWD curves with various degrees of SCB, and the cumulative intensity was plotted against the degree of SCB. This kind of plot was repeated for various molecular weights. Then the points having the same height were plotted on a map ( $X$ axis, molecular weight, $Y$ axis, degree of SCB) and linked with each other, using a microcomputer.

\section{RESULTS AND DISCUSSION}

\section{Molecular Structural Distribution of $A$ Whole Polymer}

The bird's eye view and contour map of LLDPE(F) are shown in Figures 1 and 2, respectively. These figures clearly show that this sample is mainly composed of three tops. The highest one is characterized by a very distinctive sharp peak of low SCB and high molecular weight. This is a common component of all kinds of LLDPE produced with various polymerization processes, and some superiorities in thermal and mechanical properties compared to HP-LDPE are considered to be related to the presence of this component. The middle one is the component having the average degree of SCB and molecular weight, and the lowest one is composed of the polymers of the highest degree of SCB and the lowest molecular weight. Contrary to the LLDPE sample, HP-LDPE $(\mathrm{H})$ has characteristic sharp CCD composed of a single top and wide MWD as shown in Figure 3. The sectional view of Figure 2 at a definite molecular weight $\left(\bar{M}_{w}=6.3 \times 10^{4}\right)$ gives CCD composed of multipeaks, each of which has been proved to follow a Poisson distribution (eq 1) as shown in Figure 4, 


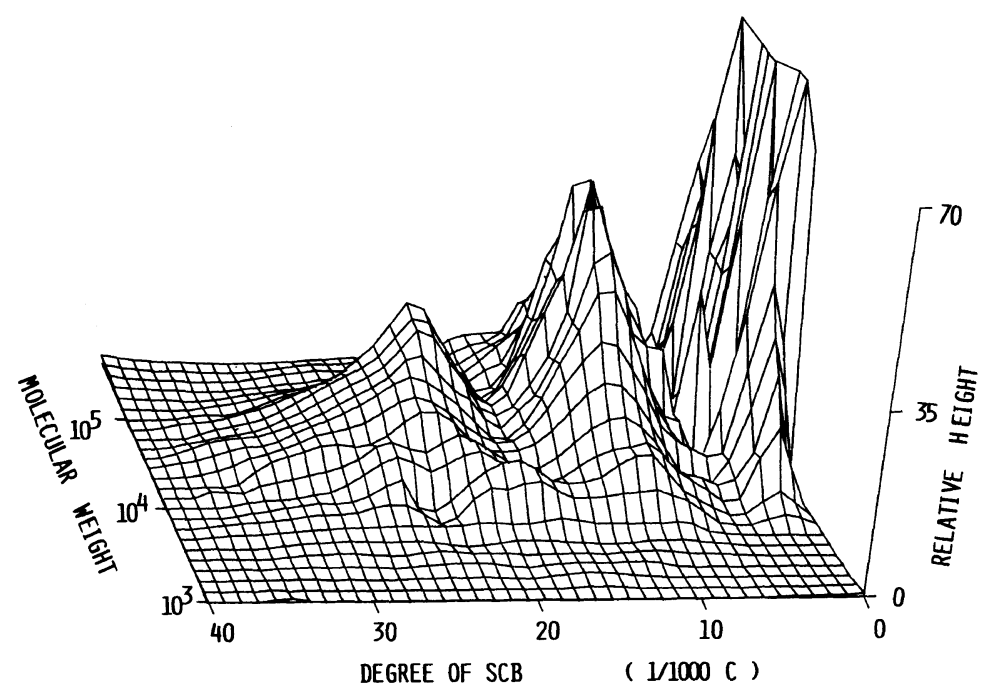

Figure 1. Bird's eye view of $\operatorname{LLDPE}(\mathrm{F})$.

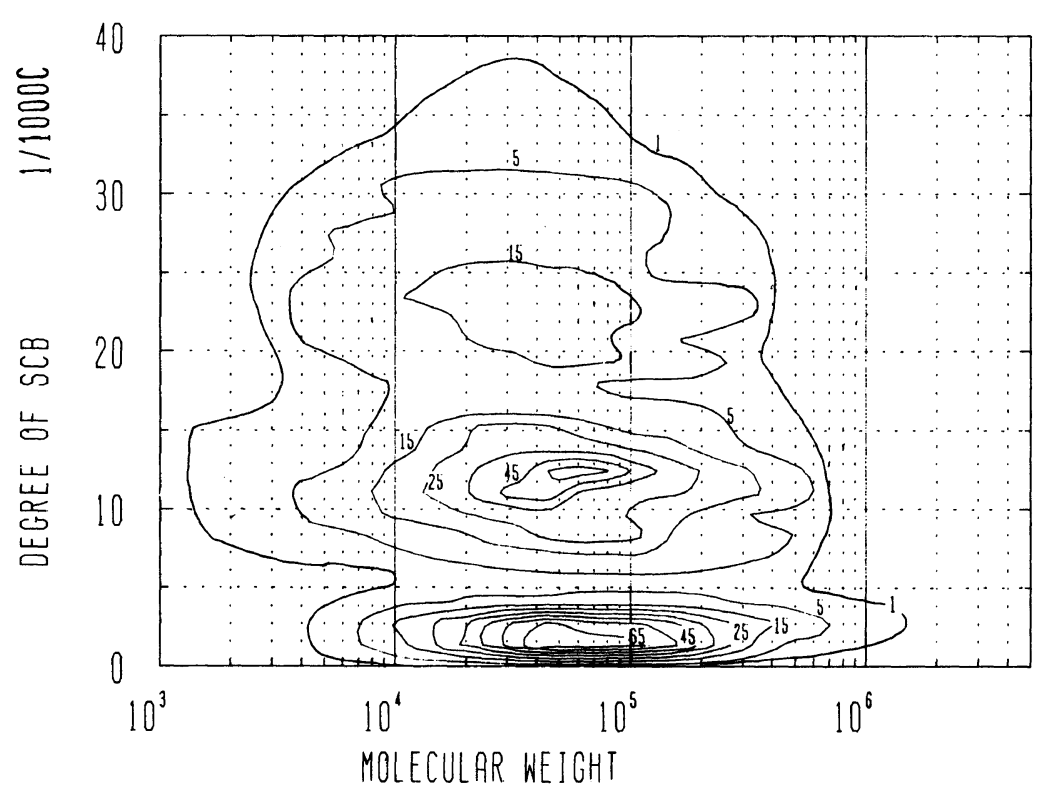

Figure 2. Contour map of $\operatorname{LLDPE}(\mathrm{F})$.

$$
P_{n k}=(n p)^{k} \cdot \mathrm{e}^{-n p} / k !
$$

where $P_{n k}$ is the probability that a molecule of $n$ carbon atoms has $k$ SCBs, $p$ the probability of SCB at each carbon atom and corresponds to average degree of SCB. $n$ is taken as 4500 in this case to fit the order of molecular weight at the sectional position. As for a HP-LDPE polymerized under uniform condition, Shirayama et $a l .{ }^{14)}$ have reported that the intermolecular distribution of SCB follows a Poisson distribution, too. Though the mechanism of the occurrence of SCB is quite different between HP-LDPE and LLDPE, this 


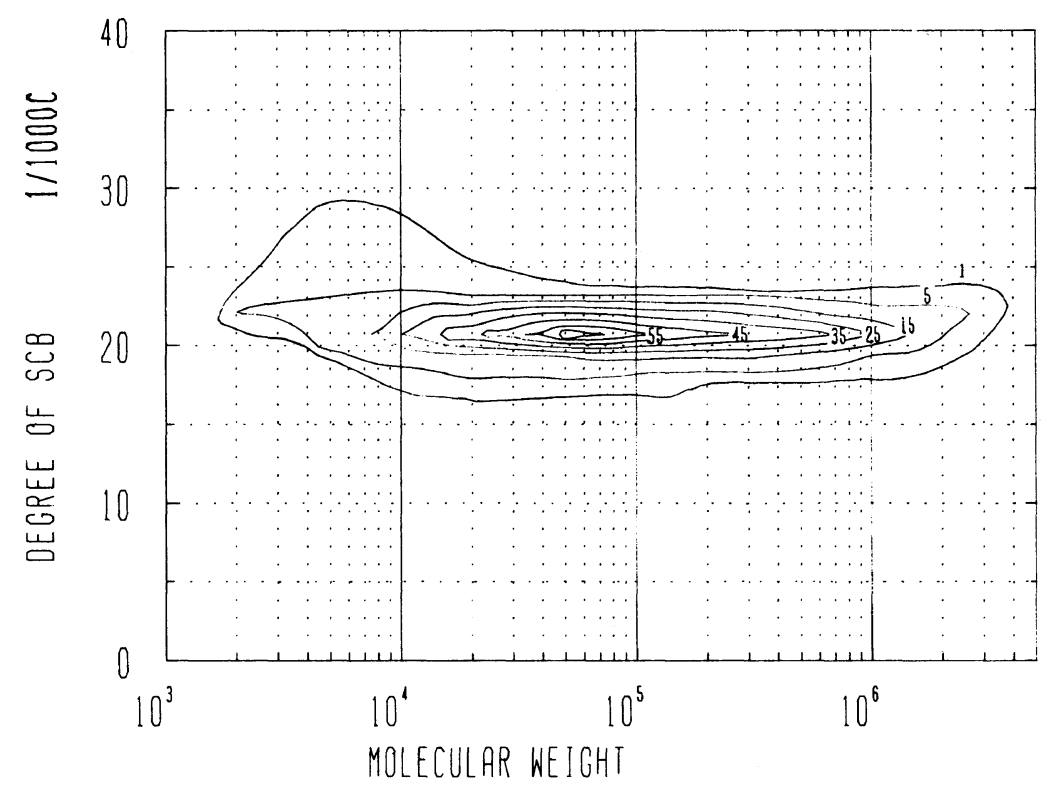

Figure 3. Contour map of HP-LDPE(H).

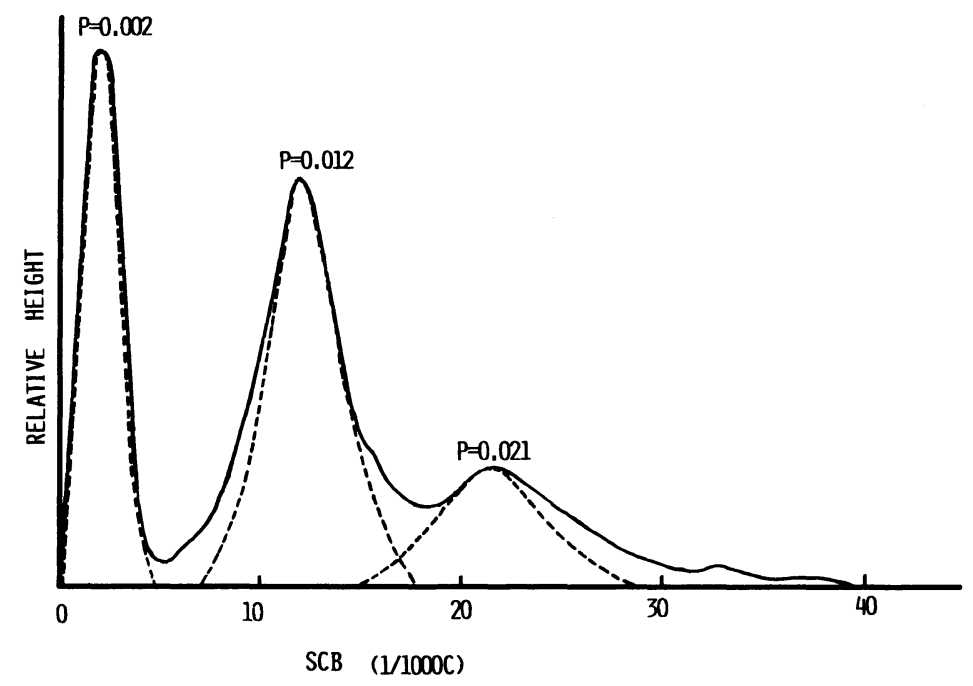

Figure 4. Sectional view of the contour map of $\operatorname{LDDPE}(\mathrm{F})$ at molecular weight of $6.3 \times 10^{4}$. Dotted lines show Poisson distributions under each probability of $\operatorname{SCB}(p)$.

result suggests that ethylene copolymerizes with $\alpha$-olefin on the basis of some definite probability on each active site on a catalyst surface if the multi-peaks in Figure 4 reflect various active sites whose reactivities to ethylene and $\alpha$-olefin differ with each other.

\section{Characterization of Fractions of SGEF}

A typical result of SGEF is shown in Table II. It is found that fractions having considerably narrow MWD were obtained by this fractionation technique, and the effect of methyl end group on the degree of SCB is 
Table II. A typical result of solvent gradient fractionation (SGEF) for LLDPE(B)

\begin{tabular}{|c|c|c|c|c|c|c|c|c|c|}
\hline \multirow{2}{*}{ No. } & \multirow{2}{*}{$\frac{\text { Fraction }}{w t \%}$} & \multirow{2}{*}{$\frac{\text { Weight }^{\mathrm{a}}}{\mathrm{g}}$} & \multirow{2}{*}{$\frac{[\eta]^{\mathrm{b}}}{\mathrm{dl} \mathrm{g}^{-1}}$} & \multirow{2}{*}{$\begin{array}{l}\bar{M}_{w}{ }^{c} \\
\times 10^{4}\end{array}$} & \multirow{2}{*}{$\frac{\begin{array}{c}\text { Total }^{\mathrm{d}} \\
\mathrm{CH}_{3}\end{array}}{1 / 1000 \mathrm{C}}$} & \multirow{2}{*}{$\frac{\mathrm{SCB}^{\mathrm{e}}}{1 / 1000 \mathrm{C}}$} & \multirow{2}{*}{$\bar{M}_{w} / \bar{M}_{n}^{\mathrm{f}}$} & \multirow{2}{*}{$\frac{\text { Density }^{\mathrm{g}}}{\mathrm{g} \mathrm{cm}^{-3}}$} & \multirow{2}{*}{$\frac{X_{\mathrm{c}}^{\mathrm{h}}}{\%}$} \\
\hline & & & & & & & & & \\
\hline 1 & 1.69 & 0.506 & 0.04 & 0.05 & - & - & - & - & - \\
\hline 2 & 3.64 & 1.091 & 0.14 & 0.31 & 29.0 & 27.1 & 1.1 & 0.9336 & 77.2 \\
\hline 3 & 2.58 & 0.775 & 0.29 & 0.87 & 26.6 & 24.9 & - & - & - \\
\hline 4 & 3.86 & 1.159 & 0.38 & 1.27 & 25.6 & 23.8 & 1.1 & 0.9287 & 72.7 \\
\hline 5 & 4.48 & 1.345 & 0.54 & 2.09 & 25.1 & 23.7 & - & - & - \\
\hline 6 & 6.56 & 1.968 & 0.64 & 2.66 & 24.9 & 23.6 & 1.1 & 0.9279 & 65.3 \\
\hline 7 & 8.14 & 2.442 & 0.70 & 3.02 & 21.9 & 21.3 & - & - & - \\
\hline 8 & 10.60 & 3.176 & 1.05 & 5.37 & 20.7 & 20.1 & 1.2 & 0.9207 & 61.8 \\
\hline 9 & 6.23 & 1.869 & 1.14 & 6.03 & 19.0 & 18.7 & - & - & - \\
\hline 10 & 16.21 & 4.872 & 1.62 & 9.93 & 17.7 & 17.4 & 1.2 & 0.9186 & 59.0 \\
\hline 11 & 13.80 & 4.151 & 2.38 & 17.1 & 10.7 & 10.5 & - & 0.9198 & 61.3 \\
\hline 12 & 11.61 & 3.479 & 2.77 & 21.3 & 9.0 & 8.9 & 1.7 & - & - \\
\hline 13 & 7.05 & 2.114 & 3.85 & 33.9 & 7.3 & 7.2 & - & 0.9254 & 64.6 \\
\hline 14 & 1.23 & 0.369 & 4.26 & 39.1 & 6.5 & 6.4 & - & - & - \\
\hline 15 & 0.77 & 0.232 & - & - & - & - & - & - & - \\
\hline 16 & 0.32 & 0.097 & - & - & - & - & - & - & - \\
\hline 17 & 0.31 & 0.093 & - & - & - & - & - & - & - \\
\hline
\end{tabular}

a Initial sample weight, $30.01 \mathrm{~g}$; the sum of fractions, $29.74 \mathrm{~g}$ (recovery, $99.1 \%$ ).

b Measured at $135^{\circ} \mathrm{C}$ in trichlorobenzene.

c Calculated from the intrinsic viscosity (see the text).

d Total degree of $\mathrm{CH}_{3}$ group per $1000 \mathrm{C}$ measured by IR spectroscopy.

e The degree of SCB after correction for end group.

${ }^{\mathrm{f}}$ Calculated from SEC data after correction for instrumental spreading.

g Measured at $23^{\circ} \mathrm{C}$.

${ }^{\text {h }}$ Crystallinity measured by X-ray diffractometer.

fairly large for small molecules but it can be ignored for fractions having a molecular weight higher than about $3 \times 10^{4}$, considering experimental error.

The degree of SCB decreased with increasing molecular weight, especially above the molecular weight of $1 \times 10^{5}$ as shown in Figure 5. This tendency was characteristic of all kinds of LLDPE used in this study, and was quite different from the results of HP-LDPE ${ }^{14}$ polymerized under an uniform conditions and those of ethylene/ $\alpha$-olefin copolymer polymerized with a soluble catalyst system such as ethyl aluminum sesquichloride/vanadium chloride. ${ }^{20}$ In the case of the latter two polymers, the degree of SCB is known to be almost independent of molecular weight in the range of high molecular weight.
Specific dependence of density and crystallinity on molecular weight can be seen in Figure 5, where both properties first decrease with increasing molecular weight, reach a minimum value at molecular weight of about $1 \times 10^{5}$, and then show opposite dependence on molecular weight. According to the theory proposed by Iida $^{21}$ for crystallization of polyethylene from melt, crystallinity decreases with increase of molecular weight because the fraction concerning the entanglement in a molecule which cannot crystallize through the retardation of molecular movement increasing with increasing molecular weight, and crystallinity $X$ is derived thermodynamically,

$$
X=1-\frac{l_{\mathrm{o}}}{l_{\mathrm{c}}} \sqrt{\frac{C k T}{a_{\mathrm{o}} L_{\mathrm{o}} \Delta f}}\left(1-\frac{2 M_{\mathrm{e}}}{M_{n}}\right)
$$




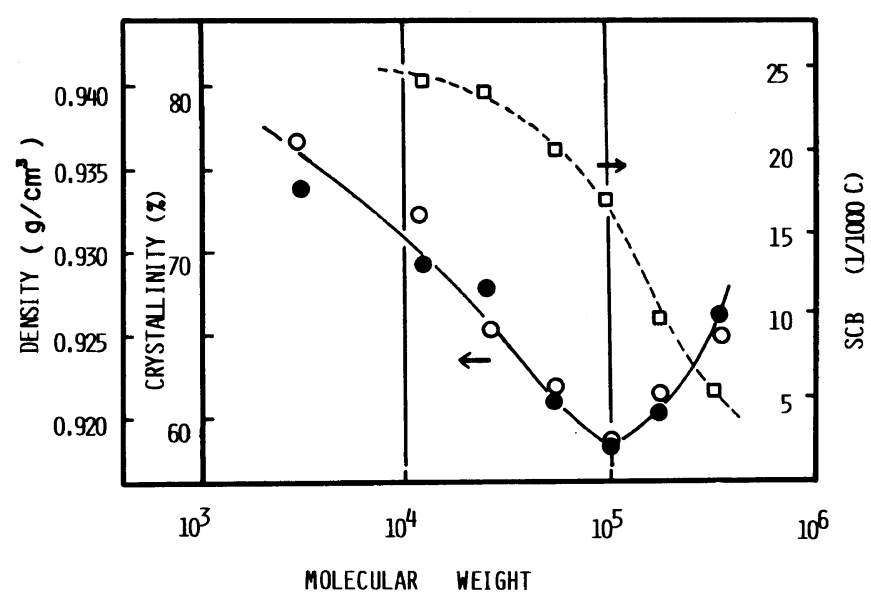

Figure 5. Molecular weight dependences of short chain branching (SCB), density (O) and crystallinity (O) for fractions of $\operatorname{LLDPE}(B)$.

$$
\Delta f=\Delta H\left(T_{\mathrm{m}}-T\right) / T_{\mathrm{m}}
$$

where $l_{\mathrm{o}}$ is the bond length of a rotational unit, $l_{c}$ the length of a rotational unit in crystal (1.54 $\AA$ and $1.27 \AA$, respectively), $C$ extension factor in melt (6.7), $k$ the Boltzman constant, $T$ the temperature $(295 \mathrm{~K}), T_{\mathrm{m}}$ melting temperature, $a_{\mathrm{o}}$ the sectional area of a chain in crystal $\left(18.7 \AA^{2}\right), L_{\mathrm{c}}$ lamella thickness, $\bar{M}_{\mathrm{e}}$ numberaverage molecular weight of chain between adjacent entanglement ( 5000 was used here ${ }^{21}$ ), $\bar{M}_{n}$ number-average molecular weight of polymer, $\Delta f$ free energy of fusion, and $\Delta H$, the heat of fusion $\left(2.78 \times 10^{8} \mathrm{~J} \mathrm{~cm}^{-3}\right)$.

As for ethylene/ $\alpha$-olefin copolymer containing ethylene of $x_{\mathrm{a}}$ mole fraction, the equilibrium melting temperature $\left(T_{\mathrm{m}}\right)$ and lamella thickness (1) can be obtained using the Flory equation 4 and the Thomson-Gibbs equation 5 , respectively,

$$
\begin{aligned}
& 1 / T_{\mathrm{m}}-1 / T_{\mathrm{m}}{ }^{\mathrm{o}}=-\frac{R}{\Delta H} \ln x_{\mathrm{a}} \\
& T_{\mathrm{m}}\left(L_{\mathrm{c}}\right)=T_{\mathrm{m}}\left(1-2 \sigma_{\mathrm{e}} / \Delta H L_{\mathrm{c}}\right)
\end{aligned}
$$

where $R$ is the gas constant, $\sigma_{\mathrm{e}}$ surface free energy $\left(87 \mathrm{~J} \mathrm{~m}^{-2}\right){ }^{22}$

The molecular weight dependence of crystallinity for copolymers with various degrees of

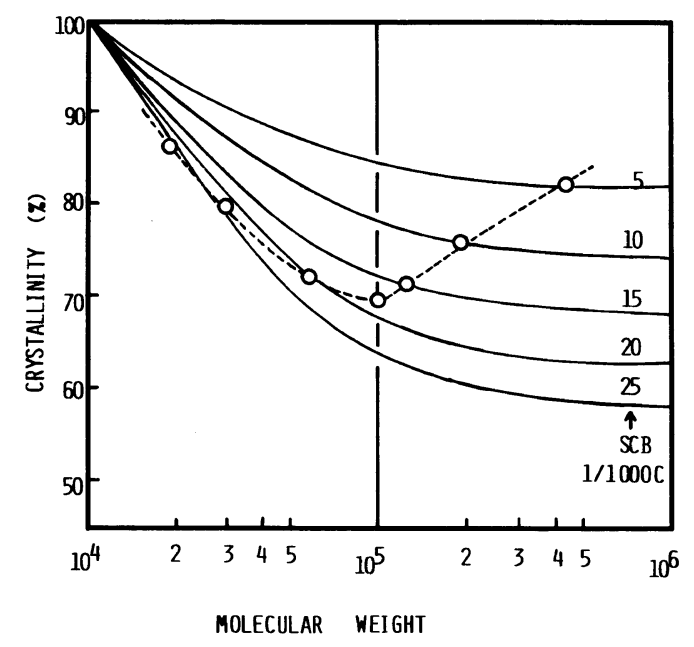

Figure 6. Theoretical dependence of the crystallinity of copolymers having various degrees of short chain branching (SCB). Dotted line denotes the experimental relationship between SCB and molecular weight.

SCB was calculated and shown in Figure 6. It was proved that crystallinity is greatly influenced by molecular weight in the molecular weight range of $1 \times 10^{4}-1 \times 10^{5}$, and is not so much affected by molecular weight but by the degree of SCB in that over $1 \times 10^{5}$. The experimental results on the relation between the degree of SCB and molecular weight for LLDPE(B) fractions are plotted in the same 


\section{S. HOSODA}

figure. As the molecular weight in eq 3 is number average one $\left(\bar{M}_{n}\right)$, the experimental molecular weight $\left(\bar{M}_{w}\right)$ was converted to $\bar{M}_{n}$ using SEC result for $\bar{M}_{w} / \bar{M}_{n}$. A concave-type dependence of crystallinity on molecular weight was obtained by connecting the points with a dotted line, which is similar to the experimental results shown in Figure 5 through the absolute value of crystallinity is different between the experiment and theory mainly because quenched samples were used in the experiment. This suggests that the unique dependence of crystallinity on molecular weight for LLDPE fraction would be attributable to the effects both of average molecular weight of a fraction and the characteristic dependence of the degree of SCB on molecular weight.

\section{$C C D$ and Crystallinity Distribution}

The fractions by SGEF technique having molecular weight of about $1 \times 10^{5}$ were further fractionated into $17-18$ fractions by TREF (cross-fractionation).

Typical results for LLDPE(B) fraction No. 10 are summarized in Table III. It is found that LLDPE fraction by SGEF is composed of various copolymers whose chemical compositions, melting temperatures and crystallinities are largely different with each other. For example, the degree of SCB disperses in the range of $1-40(1 / 1000 \mathrm{C})$, and melting temperature also disperses in the range of 60 $130^{\circ} \mathrm{C}$.

To express the degree of CCD more quantitatively, standard deviation $(\sigma)$ and coefficient of variation $(\sigma / \bar{x}: \bar{x}$ is the average degree of SCB) were calculated for some LLDPE fractions (Table IV). Many differences in $\sigma$

Table III. A typical result of temperature rising elution fractionation for LLDPE(B) No. 10 fraction

\begin{tabular}{|c|c|c|c|c|c|c|}
\hline \multirow{2}{*}{ No. } & \multirow{2}{*}{$\begin{array}{c}\begin{array}{c}\text { Extraction } \\
\text { temp. }\end{array} \\
\frac{{ }^{c} \mathrm{C}}{}\end{array}$} & \multirow{2}{*}{$\frac{\text { Fraction }^{\mathrm{a}}}{\mathrm{wt} \%}$} & \multirow{2}{*}{$\frac{\mathrm{SCB}^{\mathrm{b}}}{1 / 1000 \mathrm{C}}$} & \multirow{2}{*}{$\frac{\text { Crystallinity }}{\mathrm{wt}^{\mathrm{c}} \%}$} & \multirow{2}{*}{$\frac{T_{\mathrm{m}}{ }^{\mathrm{d}}}{{ }^{\circ} \mathrm{C}}$} & \multirow{2}{*}{$\frac{\Delta H_{\mathrm{f}}^{\mathrm{e}}}{\mathrm{cal} \mathrm{g}^{-1}}$} \\
\hline & & & & & & \\
\hline $\mathrm{X} 1$ & 25 & 4.26 & 43.3 & - & 61.4 & 6.4 \\
\hline $\mathrm{X} 2$ & 40 & 0.32 & - & - & 73.4 & 7.3 \\
\hline $\mathrm{X} 3$ & 50 & 5.75 & 33.6 & 41.0 & 82.5 & 10.9 \\
\hline $\mathrm{X} 4$ & 55 & 5.12 & 28.9 & 45.5 & 89.6 & 11.0 \\
\hline $\mathrm{X} 5$ & 58 & 7.34 & 25.5 & - & 97.3 & 13.0 \\
\hline X6 & 61 & 2.58 & 24.2 & - & 99.5 & 14.5 \\
\hline$\times 7$ & 64 & 5.21 & 22.2 & 54.2 & 101.9 & 15.3 \\
\hline $\mathrm{X} 8$ & 67 & 7.17 & 19.2 & - & 105.4 & 16.2 \\
\hline $\mathrm{X} 9$ & 70 & 8.24 & 17.4 & 55.2 & 108.2 & 17.4 \\
\hline X10 & 73 & 11.71 & 14.2 & 62.7 & 111.8 & 19.9 \\
\hline X11 & 76 & 2.14 & 11.0 & - & 114.2 & 20.8 \\
\hline $\mathrm{X} 12$ & 79 & 5.83 & 10.5 & 69.0 & 115.6 & 21.1 \\
\hline $\mathrm{X} 13$ & 82 & 7.75 & 8.5 & 71.0 & 118.7 & 23.8 \\
\hline X14 & 85 & 4.36 & 7.2 & 73.0 & 120.9 & 26.5 \\
\hline X15 & 90 & 15.74 & 4.2 & 75.8 & 126.1 & 29.4 \\
\hline $\mathrm{X} 16$ & 95 & 5.73 & 1.6 & 82.2 & 131.8 & 38.1 \\
\hline $\mathrm{X} 17$ & 100 & 0.56 & - & - & 132.5 & 41.0 \\
\hline X18 & 125 & 0.17 & - & - & - & - \\
\hline \multicolumn{7}{|c|}{$\begin{array}{l}\text { a Initial sample weight, } 3.00 \mathrm{~g} \text {; the sum of fractions } \\
\text { b Degree of SCB after correction for end group. } \\
\text { c Crystallinity measured by X-ray diffractometer. } \\
\text { d Melting peak temperature. }\end{array}$} \\
\hline
\end{tabular}




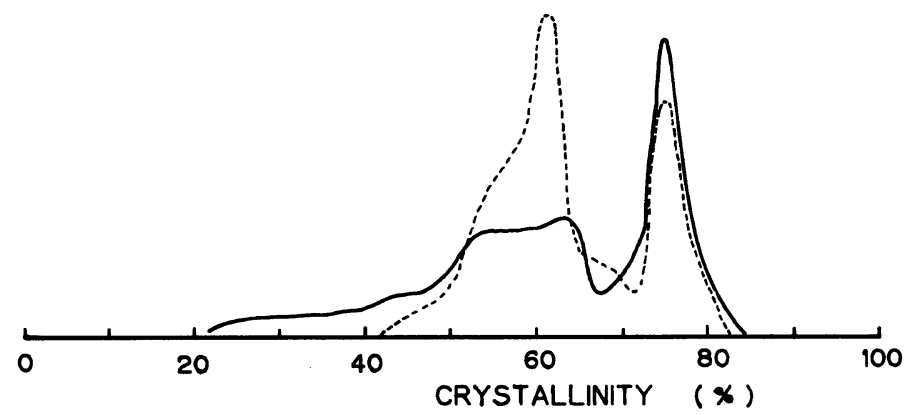

Figure 7. Crystallinity distribution of the fractions by SGEF. —- LLDPE(A) No. 10; -----, LLDPE(F) No. 10.

and $\sigma / \bar{x}$ were recognized though fractions by SGEF studied here have the same degree of density. This would be due to differences of the polymerization process and catalyst used.

The distributions of the crystallinity for two kinds of LLDPE fractions are interpreted as differential curves in Figure 7. Though both samples have the same order of crystallinity $(\sim 63 \%)$ and density before crossfractionation, the distribution is much different between two samples. This is considered to be caused by the difference of CCD (Table IV) and the kind of SCB.

\section{Thermal Analysis of Fractions}

DSC endothermic curves of LLDPE(B) fraction No. 10 and some of its cross-fractions are shown in Figure 8. The DSC curve of fraction No. 10 had a common characteristic for ordinary LLDPEs, i.e., a sharp peak at around $122^{\circ} \mathrm{C}$ and a broad one tailing to low temperature. The former is common to all kinds of commercial LLDPEs, and the intensity of the second one differs from the others depending upon polymerization conditions no matter if the densities of samples are in the same range. Each curve of crossfractions shows a single peak, suggesting narrow distribution of chemical composition. Melting peak temperature and the heat of fusion increase with decreasing degree of SCB as shown in Table III and Figure 8.

Though the cross-fractions, X15-X17,

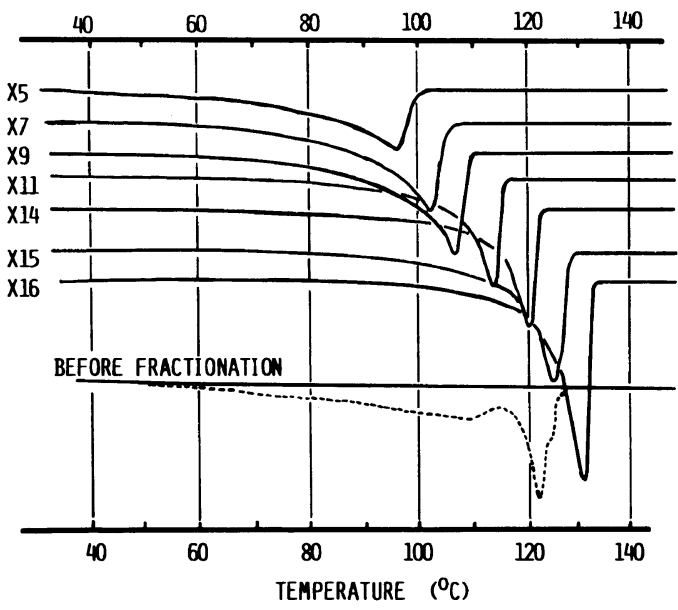

Figure 8. DSC endothermic curves of the fraction No. 10 of LLDPE(B) (-- ) and its cross-fractions (- - ).

which contain very few comonomers (butene1) in a polymer chain, show melting peak temperatures above $126^{\circ} \mathrm{C}$, the endothermic curve of the sample before cross-fractionation does not have any peak in this region. This is considered to be due to melting temperature depression which occurs in unfractionated samples on account of good miscibility among component polymers. The melting temperature of one component in a blend $\left(T_{\mathrm{m}}\right)$ is given by the following eq 6 proposed for the blends of high polymers, ${ }^{23}$

$$
1 / T_{\mathrm{m}}-1 / T_{\mathrm{m}}{ }^{\mathrm{o}}=-\frac{R V_{2 \mathrm{u}}}{\Delta H V_{1 \mathrm{u}}} \chi_{12}\left(1-v_{2}\right)^{2}
$$

where $T_{\mathrm{m}}{ }^{\mathrm{o}}$ is the melting temperature of the 
original cross-fraction, $R$ the gas constant, $\Delta H$ the heat of fusion per $\mathrm{CH}_{2}$ unit, $V_{1 \mathrm{u}}$ and $V_{2 \mathrm{u}}$ the molar volume of components 1 and 2 , respectively, and $v_{2}$, the fraction of the component under consideration. If $\chi_{12}$ is taken as -0.02 , which was the value reported for polyethylene fractions by Smith et al., ${ }^{24}$ the melting temperature of $\mathrm{X} 15$ and $\mathrm{X} 16$ would be depressed from 132 to $124.8^{\circ} \mathrm{C}$ and from 126 to $122.1^{\circ} \mathrm{C}$, respectively, in the sample before cross-fractionation. The melting temperature after depression is consistent with the highest peak of the endothermic curve of LLDPE(B) No. 10 fraction. The cross-fractions, X8$\mathrm{X} 10$, whose degrees of SCB are near the average one of the unfractionated sample, have their melting temperatures in the range of $100-115^{\circ} \mathrm{C}$. These peaks correspond to the broad second peak at around $110^{\circ} \mathrm{C}$ of unfractionated sample. Taking these results into consideration, it was found that the endothermic curve of the sample before crossfractionation is assumed to explicitly reflect its CCD.

Then, the index reflecting CCD was proposed using DSC curve. The component of the highest melting temperature $\left(\sim 122^{\circ} \mathrm{C}\right)$ is common to all kinds of LLDPEs produced with the use of a Ziegler-Natta catalyst, and the second broad peak around $110^{\circ} \mathrm{C}$ is due to the component containing average amount of comonomer for the sample having the density of about $0.920 \mathrm{~g} \mathrm{~cm}^{-3}$. Then, the area ratio of the second peak to the first (the highest) one, which is termed DSC index "DI" and should increase with narrowing $\mathrm{CCD}$, can be considered to be one of the parameters indicating the degree of CCD. As the second peak was broad, peak area was defined as shown in Figure $9\left(\mathrm{DI}=S_{\mathrm{B}} / S_{\mathrm{A}}\right)$. The results are shown in Table IV. Comparison $\sigma / \bar{x}$ values with DI for ethylene/butene-1 copolymers makes it clear that DI is indicative of CCD. Further, for copolymers having the narrowest $\operatorname{CCD}(\sigma / \bar{x}$ : $0.57-0.60)$, the higher the $\alpha$-olefin comonomer, the larger the DI; i.e., butene-1 < hexene-1 $<$ octene-1 $\simeq$ 4-methyl-pentene-1. Since, in a strict sense, DSC endothermic curve

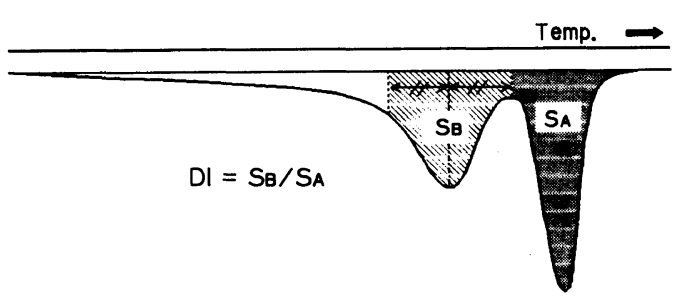

Figure 9. Shcematic representation of DSC index (DI) for DSC endothermic curve of LLDPE fraction.

Table IV. Chemical composition distribution by cross fractionation and DSC index for various LLDPE fractions

\begin{tabular}{|c|c|c|c|c|c|c|c|c|}
\hline Sample & Comonomer & $\frac{\text { Density }^{\mathrm{a}}}{\mathrm{g} \mathrm{cm}^{-3}}$ & $\begin{array}{c}\bar{M}_{w}{ }^{\mathrm{b}} \\
\times 10^{-4}\end{array}$ & $\bar{M}_{w} / \bar{M}_{n}^{\mathrm{c}}$ & $\begin{array}{c}\bar{x}^{\mathrm{d}} \\
1 / 1000 \mathrm{C}\end{array}$ & $\sigma^{\mathrm{e}}$ & $\sigma / \bar{x}$ & $\mathrm{DI}^{\mathrm{f}}$ \\
\hline LLDPE(A) No. 10 & Butene-1 & 0.919 & 9.0 & 1.1 & 17.6 & 13.0 & 0.74 & 0.48 \\
\hline LLDPE(B) No. 10 & Butene-1 & 0.919 & 9.9 & 1.2 & 16.2 & 11.0 & 0.68 & 0.52 \\
\hline LLDPE(C) No. 9 & Butene-1 & 0.921 & 8.7 & 1.1 & 15.2 & 9.5 & 0.63 & 0.66 \\
\hline LLDPE(D) No. 10 & Butene-1 & 0.920 & 11.8 & 1.3 & 12.8 & 7.3 & 0.57 & 0.96 \\
\hline LLDPE(E) No. 9 & Hexene-1 & 0.920 & 9.3 & 1.1 & 11.4 & 6.8 & 0.60 & 1.24 \\
\hline LLDPE(F) No. 10 & $\begin{array}{l}\text { 4-Methyl- } \\
\text { pentene-1 }\end{array}$ & 0.918 & 12.3 & 1.3 & 10.7 & 6.3 & 0.59 & 1.66 \\
\hline LLDPE(G) No. 9 & Octene-1 & 0.922 & $9 . .5$ & 1.2 & 8.8 & 5.0 & 0.57 & 1.56 \\
\hline
\end{tabular}

${ }^{\text {a }}$ Measured at $23^{\circ} \mathrm{C}$. ${ }^{\text {b }}$ Determined from $[\eta]$ (see the text).

c Determined by SEC after correction for axial spreading.

d The average degree of SCB of cross-fractions.

e Standard deviation. ${ }^{\mathrm{f}}$ DSC index (see the text). 
does not necessarily represent CCD itself, but the distribution of lamellar crystal thickness, ${ }^{8}$ the results shown in Table IV give important information for the relationship between CCD and lamella structures. It is quite reasonable to consider that narrow CCD results in narrow distribution of lamella thickness because the lamella crystal is composed of many polyethylene molecules of various comonomer content. This seems to be realized in the results for the samples having the same kind of comonomer (No. 1-4). But it is a matter of course that the lamella thickness does not necessarily coincide with methylene stem length that has no branching because some of SCB are known to be incorporated into a crystalline lattice for melt quenched polyethylene though the extent of incorporation varies depending on the degree and kind of SCB. ${ }^{24-30}$ If SCB is allowed to be included in a crystal, larger crystalline stems can be formed compared to those formed under the condition of complete exclusion of SCB. This would make the lamella thickness distribution spread to the direction of thicker lamella. The probability of incorporation is considered to be small for a bulkier SCB than smaller one taking the results of X-ray diffraction $^{29}$ into consideration. Thus, a copolymer of ethylene with a higher $\alpha$-olefin should have a narrower lamella thickness distribution than a copolymer with butene- 1 even if their CCDs are the same degree among the samples. This would result in larger DI of the copolymer with octene-1 or 4-methyl-pentene-1 than those with butene-1.

\section{Effect of SCB on Crystallinity and Melting Temperature}

Then, the effect of SCB on crystallinity and melting peak temperature was investigated for the cross-fractions of various ethylene $/ \alpha$ olefin copolymer fractions shown in Table IV, having molecular weights of around $1 \times 10^{5}$. As shown in Figures 10 and 11, both crystallinity and melting temperature decrease with increasing degree of SCB, and the copolymers of higher $\alpha$-olefin show lower crystallinity and melting temperature than those of butene- 1 at the same content of comonomer as follows: octene- $1 \simeq 4$-methyl-pentene- $1<$ hexene- $1<$ butene-1. This order is consistent with the degree of bulkiness of SCB. The bulky SCB should be excluded from a crystal in the amorphous region when a molecule crystallizes, and this phenomenon results in decrease of lamella thickness and increase of amorphous region. But when a molecule can crystallize even though SCB is incorporated in a crystalline stem, the crystallinity and melting temperature would not be affected so much by SCB. So the results in Figure 11 are considered to suggest the degree of the incorporation of SCB into lamella crystal. The higher melting temperature and crystallinity of LLDPE(A) than the other butene-1 copolymers would be due to the high degree of SCB blockness of LLDPE(A) as shown in Table V. The persistence ratio of LLDPE(A) $\left(N_{\mathrm{r}} / N\right)$ which represents the degree of SCB blockness is 1.15 , compared to 1.04 of $\operatorname{LLDPE}(\mathrm{C})$.

\section{Statistical Treatment for SCB Inclusion}

The possibility and degree of the incorporation of a certain kind of SCB are important problems in connection with the selection of comonomer of LLDPE, and this problem has been discussed for a long time using various methods as mentioned above. Swan et al. ${ }^{25}$ investigated the structure of a crystalline unit cell for ethylene/ $\alpha$-olefin copolymer by X-ray diffraction and found that a methyl branch can be incorporated into a crystalline lattice resulting in remarkable increase of the a-axis of a unit cell. Shirayama et al. ${ }^{30}$ also discussed the incorporation of SCB from melting temperature depression of various kinds of ethylene $/ \alpha$ olefin copolymer fractions, though the effect of molecular weight seems to appear in addition to that of SCB because molecular weights of the samples were not in the same range. Calleja et al. $^{28}$ and Hosemann et al. $^{29}$ calculated the degree of incorporation of SCB in a crystal for 


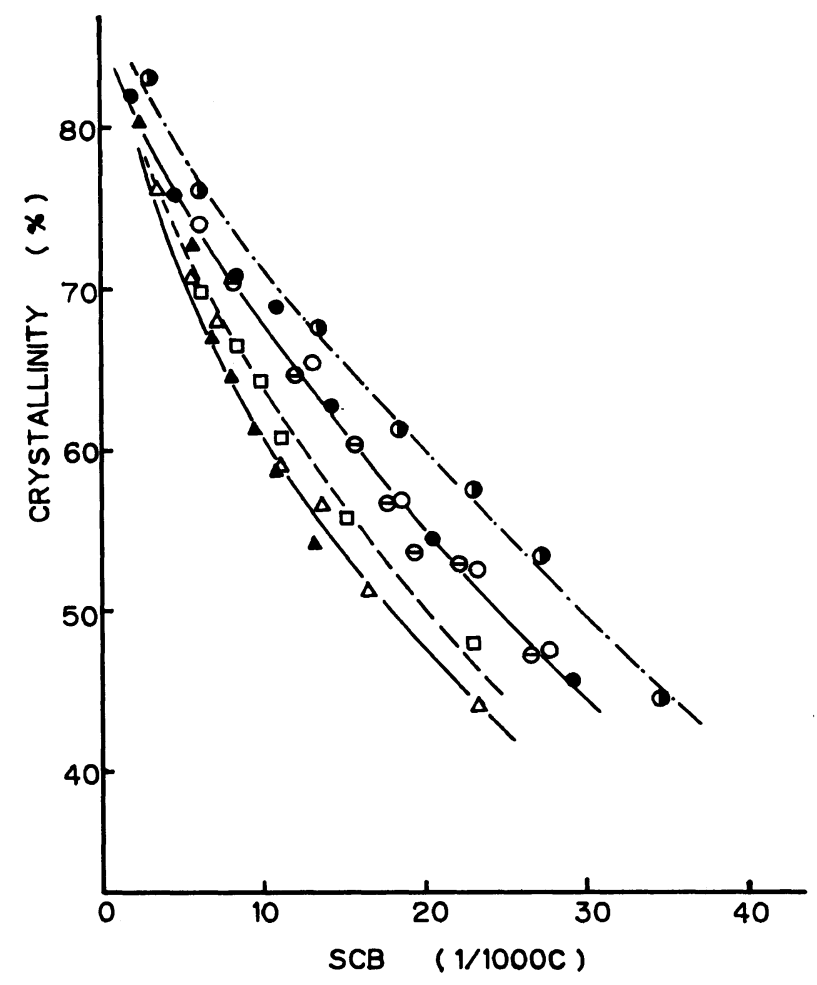

Figure 10. Relationships between crystallinity and the degree of short chain branching for crossfractions of various ethylene/ $\alpha$-olefin copolymers. $O$, LLDPE(A) No. 10; O, LLDPE(B) No. 10; $\bigcirc$, LLDPE(C) No. 9; O, LLDPE(D) No. 10; $\square$, LLDPE(E) No. 9; $\triangle$, LLDPE(F) No. 10; $\Delta, \operatorname{LLDPE}(G)$ No. 9; $\alpha$-olefin, butene-1 for $\operatorname{LLDPEs}(\mathrm{A})$-(D) hexene-1 for $\operatorname{LLDPE}(\mathrm{E})$, 4-methyl-penten-1 for LLDPE(F), octene-1 for $\operatorname{LLDPE}(\mathrm{G})$.

a HP-LDPE whole polymer from the expansion of crystalline lattice using $\mathrm{X}$-ray diffraction. Salazar and Calleja ${ }^{31}$ have investigated the relation between degree of SCB and crystallinity mainly for HP-LDPE (unfractionated) and estimated the probability of the incorporation of SCB in a crystal from statistical treatment.

The same kind of approach was tried here for the cross-fractions of LLDPE following the authors above. The probability that $j$ branchings are found in $v$-methylenes in crystal is given by a binominal distribution,

$$
P(j)={ }_{\nu} C_{\mathrm{j}} \varepsilon(1-\varepsilon)^{\nu-j}
$$

where $\varepsilon$ is the probability of the occurrence of branching per methylene. If the stem having $i$ branchings is allowed to crystallize, the weight fraction of crystalline segments (crystallinity) is the summation of crystals which contain branchings from zero up to a maximum number $i$.

$$
\alpha^{i}=\sum_{j=0}^{i} \alpha_{j}
$$

where $\alpha_{j}$ is equal to the single probability of a crystalline stem with $j$ branchings, $P(j)$, under the normalization condition

$$
\sum_{j=0}^{i} P(j)=1 .
$$

Further, since the crystallinity is really dependent on crystallization conditions, the factor " $\mu_{j}$ " is introduced, 


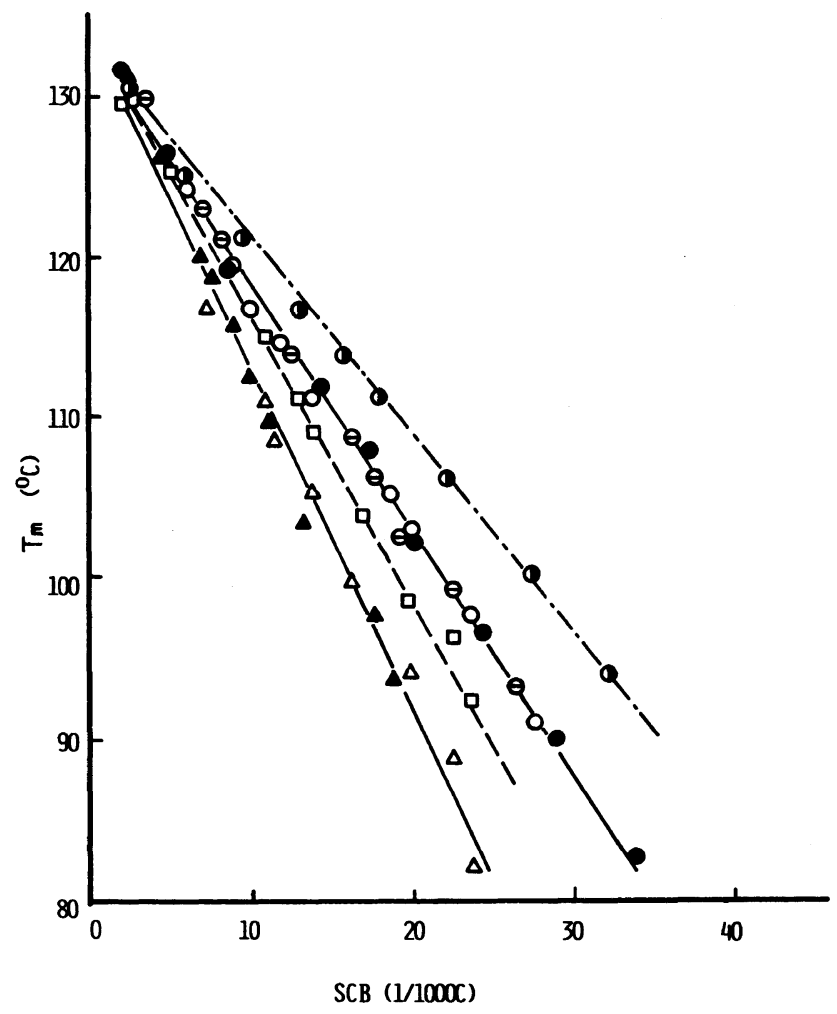

Figure 11. Relationship between melting temperature and the degree of short chain branching for crossfractions of various ethylene/ $\alpha$-olefin copolymers. Symbols are the same as in Figure 10.

Table V. Sequence distribution of ethylene/butene-1 copolymers

\begin{tabular}{|c|c|c|c|c|c|c|c|c|c|c|c|c|}
\hline \multirow{2}{*}{ Sample } & \multirow{2}{*}{$\frac{\text { Butene-1 }}{\mathrm{mol} \%}$} & \multicolumn{2}{|c|}{ Av. sequence length } & \multicolumn{6}{|c|}{ Triad distribution $^{c}$} & \multicolumn{3}{|c|}{ Rnu No. } \\
\hline & & $\bar{n}_{\mathrm{E}}^{\mathrm{a}}$ & $\bar{n}_{\mathrm{B}}^{\mathrm{b}}$ & EBE & EBB & BEB & BEE & BBB & EEE & $\bar{N}$ & $\bar{N}_{\mathrm{r}}^{\mathbf{d}}$ & $\bar{N}_{\mathrm{r}} / \bar{N}$ \\
\hline LLDPE(A) & 5.53 & 20.9 & 1.22 & 0.037 & 0.016 & 0.005 & 0.068 & 0.002 & 0.871 & 4.52 & 5.20 & 1.15 \\
\hline LLDPE(C) & 3.73 & 26.2 & 1.01 & 0.033 & 0.001 & 0.002 & 0.073 & 0.000 & 0.891 & 3.45 & 3.59 & 1.04 \\
\hline
\end{tabular}

a Average sequence length of ethylene. ${ }^{b}$ Average sequence length of butene- 1 .

c E, ethylene; B, butene-1. ' Run number of ideal random copolymers.

$$
\alpha^{i}=\sum \mu_{i} \alpha_{j}\left(0 \leqq \mu_{j} \leqq 1\right)
$$

The rate of cooling of the sample was about $340^{\circ} \mathrm{C} \mathrm{min}$ min $^{-1}$ under the crystallization conditions used here. The ratio of the crystallinity of the sample studied here to that crystallized isothermally was $0.89-0.91$ for some samples. Then, $\mu_{j}$ was taken to be 0.9 independent of the samples. Then, the crystallinity in three different cases are interpreted as follows,

Case 1: full exclusion of SCB from a crystal.

$$
\alpha^{0}=(1-\varepsilon)^{v}=\mathrm{e}^{v} \ln (1-\varepsilon)
$$

and since $\varepsilon$ is very small $(\varepsilon \ll 1)$,

$$
\ln (1-\varepsilon) \simeq-\varepsilon
$$

then, 


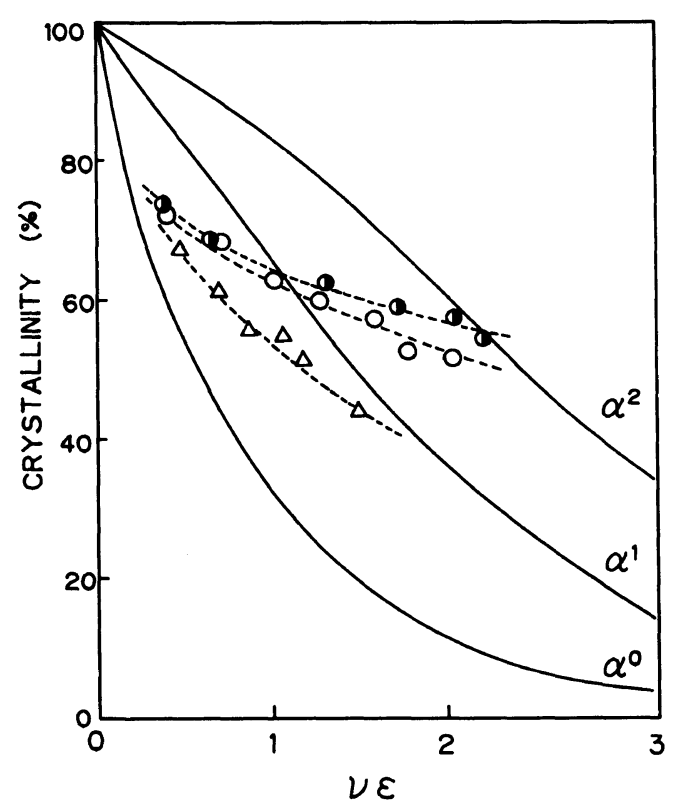

Figure 12. Relationships between crystallinity and $v \varepsilon$ ( $v \varepsilon$, number of methylene in crystal; $\alpha$, the probability of occurrence of branching per methylene). $\alpha^{0} \sim \alpha^{2}$ are the theoretical curves (see the text) and plots are the experimental results. Symbols are the same as in Figure 10.

$$
\alpha^{0} \simeq \mathrm{e}^{-v \varepsilon}
$$

Case 2: sequences with just one SCB are allowed to crystallize.

$$
\alpha^{1} \simeq \mathrm{e}^{-v \varepsilon}(1+v \varepsilon)
$$

Case 3: sequences with two SCB are allowed to crystallize.

$$
\alpha^{2} \simeq e^{-v \varepsilon}\left(1+v \varepsilon+\frac{(v \varepsilon)^{2}}{2}\right)
$$

The theoretical relationship between crystallinity and $v \varepsilon$ calculated from eq $11-13$ is shown in Figure 12, and the experimental results for the cross-fractions of ethylene/ butene- 1 and ethylene/4-methyl-pentene- 1 copolymers are plotted in the same figure. The data lie near the curve when comonomer content is small independent of the kind of SCB, which suggests almost all SCBs are excluded from the crystal. However, with increasing degree of SCB, they come close to the curve $\alpha^{1}$ for ethylene/4-methyl-pentene-1 copolymer, and to the curve $\alpha^{2}$ for ethylene/butene-1 copolymer. As for the latter samples having many $\mathrm{SCBs}(v \varepsilon \simeq 2)$, the plots suggest that $\mathrm{SCB}$ can be incorporated in a crystalline stem up to two branches (so one branch in average). Then one stem contains one SCB, statistically. The differences between $\operatorname{LLDPE}(\mathrm{A})$ and $(\mathrm{C})$ are considered to be the differences of the SCB blockness as mentioned above. The data for the former sample show that the probability of the incorporation of isobutyl branch per crystalline stem comes to 0.5 with increasing degree of SCB. From these results, it is reasonable to consider that the probability of exclusion for bulky SCB such as isobutyl from a lamella crystal is twice that of ethyl branching. Consequently, bulky branching is expected to contribute to make an amorphous phase effectively and then to make CCD to reflect sharply on super structure distribution.

Acknowledgements. The author expresses his appreciation to Mr. H. Nomura and Mr. T. Hikasa for their assistance in SAXS and XRD experiments.

Thanks are also due to Sumitomo Chemical Co., Ltd. for permission to pủblish this paper.

\section{REFERENCES}

1. L. D. Cady, Broadening Horiz Linear Low Technol., 107 (1985).

2. D. R. Burfield, Makromol. Chem., 186, 2657 (1985).

3. K. Kimura, T. Shigemura, and S. Yuasa, J. Appl. Polym. Sci., 29, 3161 (1984).

4. L. Wild, T. R. Ryle, D. C. Knobeloch, and I. R. Peat, J. Polym. Sci., Polym. Phys. Ed., 20, 441 (1982).

5. S. Nakano and Y. Goto, J. Appl. Polym. Sci., 26, 4217 (1981).

6. K. Fujimoto, K. Ogawara, and N. Emura, Toyosoda Kenkyu Hokoku, 28, 89 (1984).

7. C. Bergtröm and E. Avela, J. Appl. Polym. Sci., 23, 163 (1979).

8. S. Hosoda, K. Kojima, and M. Furuta, Makromol. Chem., 187, 1501 (1986).

9. S. Hosoda and M. Furuta, Makromol. Chem., Rapid. Commun., 2, 577 (1981).

10. S. Hosoda, Makromol. Chem., 185, 787 (1984).

11. M. Furuta, S. Hosoda, and K. Kojima, J. Appl. 
Polym. Sci., 33, 401 (1987).

12. Sumitomo Chemical Co., Jpn. Patent, B80-23561 (1980).

13. S. W. Hawkins and H. Smith, J. Polym. Sci., 28, 341 (1958).

14. K. Shirayama, T. Okada, and S. Kita, J. Polym. Sci., A3, 907 (1965).

15. T. Ishige, S.-I. Lee, and A. E. Hamielec, J. Appl. Polym. Sci., 15, 1607 (1971).

16. H. Rachapudy, G. G. Smith, V. R. Raju, and W. W. Glaessley, J. Polym. Sci., Polym. Phys. Ed., 17, 1211 (1979).

17. W. Dollbopf, H. P. Grossmann, and U. Leute, Colloid. Polym. Sci., 259, 267 (1981).

18. E. T. Hsieh and J. C. Randall, Macromolecules, 15, 353 (1982).

19. S. Mori, J. Appl. Polym. Sci., 18, 2391 (1974).

20. B. K. Hunter, K. E. Russell, M. V. Scamell, and S. C. Thompson, J. Polym. Sci., Polym. Chem. Ed., 22, 1383 (1984)
21. O. Iida, Kobunshi Ronbunshu, 38, 291 (1981).

22. B. Wunderlich, "Macromolecular Physics," Vol. 1, Academic Press, New York and London, 1980.

23. T. Nishi and T. T. Wang, Macromolecules, 8, 909 (1975).

24. P: Smith and R. St. J. Manley, Macromolecules, 12, 483 (1979).

25. P. R. Swan, J. Polym. Sci., 56, 409 (1962).

26. C. H. Baker and L. Mandelkern, Polymer, 7, 71 (1966).

27. J. E. Pready, Br. Polym. J., 5, 13 (1973).

28. F. J. B. Clleja, J. C. G. Ortega, and J. M. Salazar, Polymer, 19, 1044 (1978).

29. R. Hosemann and F. J. B. Calleja, Polymer, 20, 1091 (1979).

30. K. Shirayama, S. Kita, and H. Watabe, Makromol. Chem., 151, 97 (1972).

31. J. M. Salazar and F. J. B. Calleja, Polym. Bull., 2, 163 (1980). 